\title{
GAMBARAN TINGKAT PENGETAHUAN KELUARGA TENTANG ADHD DI PAUD KECAMATAN DENPASAR UTARA
}

\author{
DESCRIPTION OF FAMILY KNOWLEDGE LEVEL ABOUT ADHD IN \\ PAUD SUB-DISTRICT OF NORTH DENPASAR \\ Ns.I Made Sudarma Adiputra,S.Kep.M.Kes ${ }^{1}$, Ns.Ni Wayan Trisnadewi, \\ S.Kep.M.Kes ${ }^{2}$, Gusti Ayu Ketut Utari Parlin ${ }^{3}$ \\ 1,2,3 STIKes Wira Medika Bali
}

\begin{abstract}
ABSTRAK
Pendahuluan : Attention Deficit Hiperactivity Disorder (ADHD) adalah sebutan untuk gangguan perilaku dengan gejala-gejala : gangguan pemusatan perhatian dan konsentrasi, impulsivitas dan hiperaktifitas. Penelitian ini bertujuan untuk mengetahui gambaran tingkat pengetahuan keluarga tentang Attention Deficit Hiperactivity Disorder (ADHD) di PAUD Kecamatan Denpasar Utara. Metode : Rancangan penelitian ini menggunakan desain penelitian deskriptif kuantitatif dengan satu variable dan pengumpulan data menggunakan kuesioner. Teknik sampling yang digunakan yaitu multistage random sampling, meliputi : teknik cluster sampling didapatkan sampel sebanyak 23 PAUD kemudian teknik kedua adalah stratified random sampling didapatkan sampel sebanyak 280 responden. Hasil : Hasil penelitian dari 280 responden didapatkan 128 orang $(42,2 \%)$ memiliki pengetahuan kurang tentang ADHD, pada indikator konsep dasar 131 orang (46,5\%) memiliki pengetahuan baik, pada indikator deteksi dini 116 orang $(41,1 \%)$ memiliki pengetahuan kurang dan pada indikator penanganan 114 orang (40,7\%) memiliki pengetahuan kurang. Diskusi : Kesimpulan yang dapat diambil bahwa tingkat pengetahuan keluarga tentang ADHD masih sangat kurang, diharapkan hasil penelitian ini dapat sebagai masukan bagi bidang kesehatan untuk meningkatkan upaya-upaya berupa health education bagi keluarga yang memiliki anak usia dini mengenai ADHD agar dampak negative dari perilaku ADHD dapat dideteksi dan ditangani lebih dini.
\end{abstract}

Kata kunci : pengetahuan, keluarga, ADHD

\section{ABSTRACT}

Introduction : Attention Deficit Hyperactivity Disorder (ADHD) is a term for behavioral disorders with symptoms : attention and concentration disorders, impulsivity and hyperactivity. This study aims to determine the description of family knowledge level about Attention Deficit Hiperactivity Disorder (ADHD) in PAUD North Denpasar District. Methode : The design of this study used a descriptive quantitative research design with one variable and data collection using questionnaires. The sampling technique used is multistage random sampling, include: cluster sampling of obtained a sample of 23 early childhood then the second technique is stratified random sampling obtained a sample of 280 respondents. Results : The results of the 280 respondents obtained 128 votes 
(42.2\%) have less knowledge about ADHD, the basic concept indicator 131 people (46.5\%) had a good knowledge level, the early detection indicator 116 people (41.1\%) have less knowledge level and on the handling indicator 114 people (40,7\%) have less knowledge level. Discussion : The conclusion can be drawn that the level of knowledge of families who have young children about ADHD is still lacking, the expected results of this study can serve as input to the health sector in order to increase efforts in the form of health education for families who have early chilhood about ADHD so that expected negative impact of ADHD behavior can be detected and handled earlier.

Keywords : knowledge, family, $A D H D$

\begin{tabular}{ll}
\hline Alamat Korespondensi & $\begin{array}{l}: \text { Perum Unud No 12B, Batubulan, Sukawati, Gianyar } \\
\text { Email }\end{array}$
\end{tabular}

\section{PENDAHULUAN}

Istilah Attention Deficit Hiperactivity Disorder (ADHD) merupakan istilah yang sering muncul pada dunia medis belakangan ini, juga diperbincangkan dalam dunia pendidikan dan psikologi. Istilah ini memberikan gambaran tentang suatu kondisi medis yang diakui secara internasional meliputi disfungsi otak, yaitu individu mengalami kesulitan dalam mengendalikan impuls, menghambat perilaku, dant tidak mendukung rentang perhatian mereka (Baihaqi dan Sugiarmin, 2010). ADHD lebih banyak ditemukan pada anak laki-laki dibandingkan perempuan dengan perbandingan 4:1 (Delphie, 2009). Di mancanegara angka kejadian ADHD rata-rata berkisar antara 3\% hingga 10\% (Paternotte dan Buitelaar, 2010).

Berdasarkan survei yang dilakukan National Survey of Children's Health (NSCH) pada tahun 2007 di Amerika Serikat, diperkirakan prevalensi ADHD pada anak usia 4-17 tahun mencapai 9,5\% dari 5,4 juta anak (Centers for Disease Control and Prevention, 2010). Terdapat 6,4 juta anak berusia antara 4 sampai 17 tahun, sebanyak $11 \%$ yang mencapai 704 anak pada kelompok tersebut menderita ADHD pada tahun 2013 di Inggris. Hal ini berarti terdapat peningkatan lebih dari 2 juta dari tahun 2007 (Putra, 2014). Pada penelitian yang dilakukan El-nemr, et.al (2015) mengungkapkan bahwa prevalensi penderita anak dengan ADHD di Mesir mencapai 19,7\% dari 600 anak (286 laki-laki dan 314 perempuan) dari usia antara 5-12 tahun. Asherson (2012) mengungkapkan bahwa data statistik menunjukan prevalensi ADHD di wilayah Asia sebesar $10 \%$ dari total keseluruhan anak.

Prevalensi ADHD di Indonesia tidak diketahui secara pasti tingkat kejadiannya. Penelitian yang dilakukan secara terbatas di Jakarta dilaporkan prevalensi ADHD sebesar $4,2 \%$, paling banyak ditemukan pada anak usia sekolah dan pada anak lakilaki (Galih, 2011). Sementara itu di Padang prevalensi mencapai 8\%, di Bantul, Yogyakarta mencapai 5,7\% (Putri 2014). Di Bali khususnya Denpasar laporan mengenai angka kejadian ADHD hanya bersumber dari laporan kasus di poliklinik atau pusat terapi tumbuh kembang anak. Menurut Indriyani, dkk (2008) menyatakan sebuah penelitian retrospektif yang dilakukan di Poliklinik Tumbuh Kembang Anak Rumah Sakit Umum Pusat Sanglah Denpasar tahun 2005-2006, yang dilakukan untuk mengetahui prevalensi, karakteristik demografi dan klinis, 
serta faktor-faktor risiko Gangguan Pemusatan Perhatian Dan Hiperaktif (GPPH). Hasil dari penelitian tersebut dari 111 subyek didapatkan prevalensi GPPH 51 $(45,9 \%)$ yang terdiri dari $43(38,7 \%)$ laki-laki dan 8 (7,2\%) perempuan. Jumlah GPPH tipe kombinasi 39 (76,5\%), GPPH tipe kurangnya perhatian $7(13,7 \%)$, dan GPPH tipe impulsivitas-hiperaktivitas sebesar $5(9,8 \%)$, anak pertama lebih banyak didapatkan pada anak dengan GPPH dan ibu yang pendidikan sarjana (Arningsih, 2016). Dari hasil penelitian lain yang dilakukan di 15 sekolah inklusi Kota Denpasar ditemukan 164 siswa-siswi ABK didapatkan anak dengan ADHD sebanyak 58 orang dengan jumlah laki-laki 49 orang dan perempuan 9 orang (Apriliya, 2017). Jumlah kunjungan anak ADHD di Pusat Terapi Anak dan Sekolah Kebutuhan Khusus Pradnyagama Denpasar selama tahun 2012 mencapai 150 anak (Adiputra dkk, 2015).Lahirnya anak dengan gangguan ADHD dalam sebuah keluarga merupakan sebuah beban yang tidak mudah bagi orang tua. Penelitian terhadap penyebab-penyebab ADHD masih tetap berlangsung, ditemukan beberapa hal sebagai penyebab ADHD yaitu: karena adanya factor genetic sebagai factor terbesar, adanya fungsi yang berbeda dalam otak dan factor lingkungan yang memegang peranan penting (Paternotte dan Buitelaar, 2010). Menurut Asmira (2015), apapun yang berlebihan atau kekurangan akan berdampak pada dirinya sendiri maupun orang lain. Anak hiperaktif yang tidak bisa diam akan menimbulkan masalah dilingkungan sekolah maupun rumah seperti: prestasi belajar yang buruk dan tidak mempunyai teman yang jelas akan membawa dampak negative untuk masa depan anak.

Menangani dan mendidik anak hiperaktif berbeda caranya dengan mendidik anak-anak normal. Point penting dalam menangani dan membantu anak dengan ADHD adalah membantunya untuk dapat memusatkan perhatian dan konsentrasi mereka. Brain gym, pembuatan mind mapping dalam setiap materi pelajaran dan problem solving dapat membantu meningkatkan konsentrasi anak ADHD. Berdasarkan hasil penelitian Nugroho (2014) tentang efek brain gym dalam meningkatkan perhatian anak ADHD dapat ditarik kesimpulan bahwa brain gym memberikan efek dalam meningkatkan perhatian anak ADHD. Jadi, sangat penting bagi keluarga dan konselor sekolah untuk menangani anak ADHD agar dampak negative dari semua tingkah lakunya tetap berada dalam kontrol dan mampu memusatkan perhatian/konsentrasinya (Richma, 2014).

Mendiagnosis anak hiperaktif perlu screening khusus yang dilakukan dengan tahapan tertentu (Asmira, 2015). Pada beberapa anak ADHD diagnosis ditegakkan sangat lambat yaitu diatas 12 tahun hal ini dapat terjadi karena terdapat factor-faktor yang dapat mengkompensasi misalnya: anak-anak ini mempunyai inteligensia di atas rata-rata orang tuanya berhasil membangun situasi keluarga dengan suasana yang nyaman serta stabil tetapi saat disekolah lanjutan dapat mengalami kegagalan. Perilaku anak ADHD dapat berubah dalam satu periode bahkan satu hari hal ini yang dapat menyebabkan orang tua bingung dalam mendeteksinya (Paternote dan Buitelaar, 2010). Tidak ada tes untuk mendiagnosis secara pasti jenis gangguan ini, dikarenakan gejala anak ADHD ini cukup bervariasi tergantung pada usia, situasi, serta lingkungannya. Namun, ada ciri utama dari seorang yang mengalami ADHD yang dapat dideteksi dini oleh keluarga maupun guru disekolah yaitu meliputi gangguan pemusatan perhatian (inatensi), gangguan pengendalian diri (impulsivitas), dan gangguan aktivitas yang berlebihan (hiperaktif) (Chrisna, 2014). 
Anak ADHD membutuhkan perhatian yang lebih untuk menempa keterampilan dan kepribadian mereka agar dapat diterima dalam masyarakat. Anak ADHD dapat sukses bila mampu mengembangkan potensi diri yang dimiliki dan mampu beradaptasi dengan lingkungan sekitarnya. Anak yang mengalami ADHD juga biasanya mempunyai kecerdasan yang di atas rata-rata namun orang tua serta keluarga mereka sering tidak menyadarinya. Peran keluarga begitu diperlukan untuk memberi dukungan moral dan material bagi kesuksesan anak ADHD. Oleh karena itu anak dengan ADHD harus dideteksi dengan dini oleh keluarga agar tumbuh dan kembangnya dapat sesuai dengan harapan orang tuanya.

Berdasarkan studi pendahuluan yang dilakukan di TK. Tunas Mekar I, Pusat PAUD Kumara Bhuana II, PAUD Loka Sari, TK. Permata Kasih dan TK. Tunas Wijaya Kecamatan Denpasar Utara pada tanggal 14-17 Februari 2018, didapatkan dari 30 keluarga yang diwawancarai 18 responden tidak dapat menjelaskan pengertian dari ADHD, 19 responden kurang mengetahui gejala anak ADHD dan 26 responden tidak mengetahui cara melakukan deteksi dini serta penanganan yang harus diberikan kepada anak ADHD di rumah. Berdasarkan hasil wawancara diatas dapat dilihat tingkat pengetahuan keluarga tentang ADHD masih rendah, keluarga yang menemani anaknya di sekolah mengaku masih asing dengan kata ADHD, ciriciri serta masih belum mengetahui penanganan untuk anak ADHD. Keluarga adalah kunci utama dan terpenting dalam mendeteksi, manangani, merawat dan mendidik anak ADHD tetapi jika lingkungan pertama anak sudah tidak mengetahui, tidak dapat mendeteksi bahkan tidak tau penangananya secara dini maka akan memperparah dampak negative dari perilaku anak ADHD kedepannya. Sehingga perlu dilakukan penelitian lebih lanjut untuk mengetahui bagaimanakah gambaran tingkat pengetahuan keluarga tentang ADHD.

Sehingga peneliti ingin mengetahui bagaimanakah gambaran tingkat pengetahuan keluarga tentang ADHD dengan melakukan penelitian kuantitatif deskriptif dengan judul Gambaran Tingkat Pengetahuan Keluarga tentang Attention Deficit Hiperactivity Disorder (ADHD) pada Anak di PAUD Kecamatan Denpasar Utara.. Tujuan umum pada penelitian ini adalah untuk mengetahui untuk mengetahui gambaran tingkat pengetahuan keluarga tentang Attention Deficit Hiperactivity Disorder (ADHD) di PAUD Kecamatan Denpasar Utara. Sedangkan tujuan khusus dari penelitian ini adalah untuk mengetahui gambaran tingkat pengetahuan keluarga tentang konsep dasar, deteksi dini dan penanganan Attention Deficit Hiperactivity Disorder (ADHD) di PAUD Kecamatan Denpasar Utara. BAHAN DAN METODE

Rancangan penelitian ini menggunakan metode penelitian non eksperimen yaitu deskriptif kuantitatif, penelitian ini bertujuan untuk mendiskripsikan (memaparkan) peristiwa penting yang terjadi. Deskripsi peristiwa lebih menekankan pada data faktual daripada menyimpulkan. Fenomena yang terjadi disajikan secara apa adanya tanpa ada manipulasi dari peneliti. Peneliti juga tidak boleh menganalisis bagaimana dan mengapa fenomena tersebut bisa terjadi, jadi penelitian ini tidak memerlukan adanya hipotesis (Nursalam, 2016). Populasi dalam penelitian ini adalah keluarga yang memiliki anak usia dini dan bersekolah di PAUD Kecamatan Denpasar Utara berjumlah 80 sekolah, sampel yang digunakan yaitu 280 keluarga yang memiliki anak usia dini dan bersekolah di 23 PAUD Kecamatan Denpasar Utara dengan menggunakan teknik sampling multistage random sampling yaitu proses penarikan sampel dengan beberapa tahap. Dalam 
penelitian ini tahap pertama yang digunakan adalah teknik cluster sampling (area sampling) untuk menentukan sampel bila obyek yang akan dijadikan sumber data dan yang akan diteliti sangat luas, maka pengambilan sampelnya berdasarkan populasi yang telah ditetapkan dari teknik ini didapatkan sample sebanyak 23 PAUD. Tahap kedua menggunakan teknik stratified random sampling, teknik ini digunakan bila setelah didapatkan populasi atau area dicluster mempunyai anggota/unsur yang tidak homogen dan berstrata secara proporsional (Sugiyono, 2016) dari teknik ini didapatkan sample sebanyak 280 responden. Penelitian ini dilaksanakan pada tanggal 16 April-4 Mei 2018. Penelitian dilakukan di 23 PAUD Kecamatan Denpasar Utara. Penelitian ini menggunakan instrument penelitian kuesioner karena jenis data yang digunakan dalam penelitian ini adalah data primer. Data primer yaitu data yang didapatkan oleh peneliti dari sumbernya langsung. Dimana data langsung diambil dari kuesioner yang diisi oleh responden. Menurut Nursalam (2016) analisa deskriptif adalah suatu prosedur pengolahan data secara ilmiah dalam bentuk tabel atau grafik. Data yang disajikan yaitu frekuensi, proporsi, rasio dan ukuran-ukuran kecendrungan pusat (rata-rata hitung, median, modus). Analisa yang dilakukan pada penelitian ini adalah tahap analisa deskriptif yaitu analisa pada tahap distribusi dan frekuensi. Analisa data akan dijelaskan dalam bentuk tabel.

HASIL

1. Tabel silang karakteristik responden dengan pengetahuan di PAUD Kecamatan Denpasar Utara.

\begin{tabular}{|c|c|c|c|c|c|c|c|c|}
\hline \multirow{3}{*}{$\begin{array}{l}\text { Karakteristik } \\
\text { Responden }\end{array}$} & \multicolumn{6}{|c|}{ Pengetahuan } & \multicolumn{2}{|c|}{ Total } \\
\hline & \multicolumn{2}{|c|}{ Baik } & \multicolumn{2}{|c|}{ Cukup } & \multicolumn{2}{|c|}{ Kurang } & \multirow[b]{2}{*}{$\mathbf{F}$} & \multirow[b]{2}{*}{$\%$} \\
\hline & $\mathbf{F}$ & $\%$ & $\mathbf{F}$ & $\%$ & $\mathbf{F}$ & $\%$ & & \\
\hline \multicolumn{9}{|l|}{ Usia } \\
\hline 26-35 tahun & 29 & 10,4 & 71 & 25,4 & 52 & 18,6 & 152 & 54,3 \\
\hline 36-45 tahun & 66 & 23,6 & 36 & 12,9 & 26 & 9,3 & 128 & 45,7 \\
\hline \multicolumn{9}{|l|}{ Jenis Kelamin } \\
\hline Laki-laki & 21 & 7,5 & 40 & 14,3 & 35 & 12,5 & 96 & 34,3 \\
\hline Perempuan & 34 & 12,1 & 67 & 23,9 & 83 & 29,6 & 184 & 65,7 \\
\hline \multicolumn{9}{|l|}{ Pendidikan } \\
\hline SD & 1 & 0,4 & 2 & 0,7 & 4 & 1,4 & 7 & 2,5 \\
\hline SMP & 2 & 0,7 & 5 & 1,8 & 13 & 4,6 & 20 & 7,1 \\
\hline SMA & 10 & 3,6 & 48 & 17,1 & 43 & 15,4 & 101 & 36,1 \\
\hline Perguruan Tinggi & 71 & 25,4 & 50 & 17,9 & 31 & 11,1 & 152 & 54,3 \\
\hline \multicolumn{9}{|l|}{ Pekerjaan } \\
\hline Tidak bekerja & 11 & 3,9 & 40 & 14,3 & 42 & 15,0 & 93 & 33,2 \\
\hline PNS & 14 & 5,0 & 11 & 3,9 & 2 & 0,7 & 27 & 9,6 \\
\hline Swasta & 32 & 11,4 & 72 & 25,7 & 56 & 20,0 & 160 & 57,1 \\
\hline \multicolumn{9}{|l|}{ Sumber Informasi } \\
\hline $\begin{array}{l}\text { Tidak pernah } \\
\text { mendapatkan } \\
\text { informasi }\end{array}$ & 3 & 1,1 & 73 & 26,1 & 92 & 32,8 & 168 & 60,0 \\
\hline Petugas kesehatan & 3 & 1,1 & 7 & 2,5 & 4 & 1,4 & 14 & 5,0 \\
\hline
\end{tabular}




\begin{tabular}{lcccccccc} 
Teman & 3 & 1,1 & 11 & 3,9 & 4 & 1,4 & 18 & 6,4 \\
Buku & 2 & 0,7 & 2 & 0,7 & 7 & 2,5 & 11 & 3,9 \\
TV & 6 & 2,1 & 5 & 1,8 & 11 & 3,9 & 22 & 7,9 \\
Internet & 33 & 11,8 & 9 & 3,2 & 5 & 1,8 & 47 & 16,8 \\
\hline
\end{tabular}

Tabel 1 menunjukkan bahwa dari keseluruhan responden berdasarkan karakteristik usia dan pengetahuan angka tertinggi pada usia 26-35 tahun dan memiliki pengetahuan cukup sebanyak 71 orang $(25,4 \%)$. Berdasarkan karakteristik jenis kelamin dan pengetahuan angka tertinggi pada jenis kelamin perempuan dan memiliki pengetahuan kurang sebanyak 83 orang $(29,6 \%)$. Berdasarkan karakteristik pendidikan dan pengetahuan angka tertinggi pada tingkat pendidikan perguruan tinggi dan memiliki pengetahuan baik sebanyak 71 orang $(25,4 \%)$. Berdasarkan karakteristik pekerjaan dan pengetahuan angka tertinggi pada pekerjaan swasta dan memiliki pengetahuan cukup sebanyak 72 orang $(25,7 \%)$. Berdasarkan karakteristik sumber informasi dan pengetahuan angka tertinggi pada responden yang tidak pernah mendapatkan informasi dan memiliki pengetahuan kurang sebanyak 92 orang $(32,8 \%)$.

2. Distribusi Frekuensi Responden Berdasarkan Tingkat Pengetahuan tentang Attention Deficit Hyperactivity Disorder (ADHD) Menurut Indikator

\begin{tabular}{llcc}
\hline No. & \multicolumn{1}{c}{$\begin{array}{c}\text { Tingkat } \\
\text { pengetahuan }\end{array}$} & $\begin{array}{c}\text { Frekuensi } \\
(\mathbf{f})\end{array}$ & $\begin{array}{c}\text { Persentase } \\
(\mathbf{\%})\end{array}$ \\
\hline $1 . \quad$ & Konsep dasar ADHD & & \\
& Baik & 131 & 46,5 \\
& Cukup & 112 & 40,0 \\
& Kurang & 37 & 13,2 \\
2. & Deteksi dini ADHD & 71 & \\
& Baik & 93 & 25,4 \\
& Cukup & 116 & 43,2 \\
& Kurang & & \\
3. Penanganan ADHD & 55 & 19,6 \\
& Baik & 111 & 39,6 \\
& Cukup & 114 & 40,7 \\
\hline & Kurang & 280 & 100 \\
\hline
\end{tabular}

tabel 2 menunjukan bahwa tingkat pengetahuan tentang ADHD ditinjau dari konsep dasar ADHD didapatkan bahwa sebagian responden dengan kategori baik yaitu sebanyak 131 orang (46,5\%). Apabila ditinjau dari deteksi dini ADHD didapat sebagian besar responden kategori kurang yaitu sebanyak 116 orang $(41,1 \%)$ dan dari indikator penanganan ADHD didapat sebagian besar responden kategori kurang yaitu sebanyak 114 orang $(40,7 \%)$.

3. Distribusi Frekuensi Responden Berdasarkan Tingkat Pengetahuan tentang Attention Deficit Hyperactivity Disorder (ADHD) di PAUD Kecamatan Denpasar Utara 


\begin{tabular}{cccc}
\hline No. & $\begin{array}{c}\text { Tingkat } \\
\text { Pengetahuan }\end{array}$ & $\begin{array}{c}\text { Frekuensi } \\
(\mathbf{f})\end{array}$ & $\begin{array}{c}\text { Persentase } \\
(\%)\end{array}$ \\
\hline 1. & Baik & 55 & 19,6 \\
2. & Cukup & 107 & 38,2 \\
3. & Kurang & 128 & 42,2 \\
\hline & Total & 280 & 100 \\
\hline
\end{tabular}

Tabel 3 menunjukan bahwa dari keseluruhan responden sebagian besar responden memiliki tingkat pengetahuan kurang yaitu sebanyak 128 orang $(42,2 \%)$.

\section{PEMBAHASAN}

\section{Identifikasi karakteristik keluarga yang memiliki anak usia dini}

Penelitian ini mengidentifikasi tentang data demografi yang menjadi karakteristik responden terdiri dari usia, jenis kelamin, pendidikan, pekerjaan dan sumber informasi untuk memperoleh pengetahuan tentang ADHD. Berdasarkan hasil penelitian karakteristik umur responden, menunjukkan mayoritas responden berada pada usia 26-35 tahun dan memiliki pengetahuan cukup sebanyak 71 orang sedangkan responden yang berada pada usia 36-45 tahun memiliki pengetahuan baik sebanyak 66 orang. Hasil penelitian ini sejalan dengan teori Notoadmodjo (2012), yaitu usia mempengaruhi daya tangkap dan pola pikir seseorang. Semakin bertambah usia seseorang maka daya tangkap dan pola pikirnya akan semakin berkembang. Hal ini menyebabkan pengetahuan yang diperoleh seseorang semakin baik. Hasil analisis peneliti melihat hasil penelitian semakin dewasa usia responden semakin berpengetahuan baik maka faktor usia mempengaruhi motivasi seseorang dalam mendapatkan pengetahuan tentang ADHD.

Karakteristik responden berdasarkan jenis kelamin menunjukkan mayoritas responden memiliki jenis kelamin perempuan dan memiliki pengetahuan kurang sebanyak 83 orang. Menurut Notoadmodjo (2012), yaitu apapun jenis kelamin seseorang bila dia masih produktif, berpendidikan atau berpengalaman maka ia akan cenderung memiliki pengetahuan yang tinggi. Hasil analisis peneliti banyaknya perempuan memiliki pengetahuan kurang tentang ADHD disebabkan karena banyak responden perempuan yang tidak bekerja atau sebagai ibu rumah tangga yang tentu saja tidak terlalu produktif atau berpengalaman untuk mencari informasi melalui media massa atau internet tentang ADHD.

Karakteristik responden berdasarkan pendidikan menunjukkan mayoritas responden berada pada pendidikan perguruan tinggi dan memiliki pengetahuan baik sebanyak 71 orang. Hasil penelitian ini sejalan dengan teori Notoadmodjo (2012), pendidikan merupakan suatu usaha untuk mengembangkan kepribadian dan kemampuan seseorang. Pendidikan akan mempengaruhi proses belajar seseorang karena semakin tinggi pendidikan seseorang maka semakin mudah orang tersebut menerima informasi. Hasil analisis peneliti banyaknya responden dengan pendidikan perguruan tinggi yang memiliki pengetahuan baik karena sudah mendapatkan paparan informasi atau pembelajaran sebelumnya tentang ADHD. 
Karaktersitik responden berdasarkan pekerjaan menunjukkan mayoritas responden berada pada pekerjaan swasta dan memiliki pengetahuan cukup sebanyak 72 orang. Menurut Notoadmodjo (2012), pekerjaan membatasi kesenjangan antara informasi kesehatan dan menjadi salah satu hal yang memotivasi seseorang untuk memperoleh informasi. Hasil analisis peneliti pada pekerjaan swasta memiliki pengetahuan kategori cukup dikarenakan tidak minimnya pekerjaan ini untuk menerima informasi kesehatan tentang ADHD walaupun belum maksimal sehingga pengetahuan masuk dalam kategori cukup.

Karakteristik responden berdasarkan sumber informasi menunjukkan mayoritas responden tidak pernah mendapatkan informasi tentang ADHD dan memiliki pengetahuan kurang sebanyak 73 orang. Hasil penelitian ini sejalan dengan teori Notoadmodjo (2012), informasi bisa diperoleh baik dari pendidikan formal maupun non formal sehingga menghasilkan peningkatan terhadap pengetahuan seseorang. Hasil analisis peneliti banyaknya responden yang tidak pernah mendapatkan informasi tentang ADHD dan memiliki pengetahuan kurang dikarenakan minimnya paparan informasi atau pembelajaran sebelumnya tentang ADHD.

\section{Gambaran tingkat pengetahuan keluarga tentang konsep dasar ADHD}

Hasil penelitian menunjukan bahwa hasil pengukuran terhadap responden tentang konsep dasar didominasi oleh responden berpengetahuan baik. Sesuatu hubungan sebab akibat tentang konsep dasar ADHD digolongkan dalam tingkat pengetahuan comprehension dimana keluarga yang memiliki anak PAUD mampu memahami definisi, ciri-ciri serta factor penyebab ADHD. Peneliti berasumsi dengan hasil penelitian yang menunjukkan pengetahuan responden yang tergolong kategori berpengetahuan baik hal ini menunjukkan suatu pembelajaran sebelumnya, pengalaman atau pengetahuan sebelumnya mempunyai pengaruh terhadap tingkat pengetahuan keluarga yang memiliki anak PAUD yang sudah pernah menerima informasi sebelumnya sehingga responden mampu menguraikan secara benar mengingat mayoritas tingkat pendidikan responden adalah perguruan tinggi. Hal tersebut memperkuat teori yang diungkapkan oleh Widayatun (2009), pengetahuan sangat erat kaitannya dengan pendidikan seseorang dengan pendidikan formal yang tinggi mengingat dalam penelitian ini didominasi oleh responden dengan tingkat pendididikan perguruan tinggi, biasanya akan mempunyai tingkat pengetahuan yang lebih tinggi bila dibandingkan dengan seseorang yang tingkat pendidikannya lebih rendah. Namun perlu ditekankan bahwa seseorang yang berpendidikan rendah tidak berarti mutlak berpengetahuan rendah pula.

\section{Gambaran tingkat pengetahuan keluarga tentang deteksi dini ADHD}

Hasil penelitian menunjukkan bahwa hasil pengukuran terhadap responden tentang deteksi dini didominasi oleh responden kategori pengetahuan kurang. Sesuatu hubungan sebab akibat tentang deteksi dini ADHD digolongkan dalam tingkat pengetahuan know dimana tahu (know) merupakan tingkat yang paling rendah dalam pengetahuan, keluarga yang memiliki anak PAUD belum mampu memahami bagaimana cara mendeteksi dini anak dengan ADHD. Peneliti berasumsi dengan hasil penelitian yang menunjukkan pengetahuan responden yang tergolong kategori berpengetahuan kurang hal ini 
menunjukkan kurangnya suatu pembelajaran, pengalaman atau pengetahuan sebelumnya mempunyai pengaruh terhadap tingkat pengetahuan keluarga yang memiliki anak PAUD yang belum pernah menerima informasi tentang deteksi dini ADHD sebelumnya.

\section{Gambaran tingkat pengetahuan keluarga tentang penanganan ADHD}

Hasil penelitian menunjukan bahwa hasil pengukuran terhadap responden tentang penanganan ADHD didominasi oleh responden kategori pengetahuan kurang. Sesuatu hubungan sebab akibat tentang penanganan ADHD digolongkan dalam tingkat pengetahuan know dimana tahu (know) merupakan tingkat yang paling rendah dalam pengetahuan, keluarga yang memiliki anak PAUD belum mampu memahami bagaimana cara menangani anak dengan ADHD. Menurut teori Hinshaw \& Scheffler (2014), dengan kurangnya pengetahuan tentang penanganan ADHD akibatnya keluarga akan mengalami hambatan atau keterbatasan dalam pengobatan dan anak-anak akan gagal untuk mendapatkan bantuan yang mereka harapkan. Peneliti berasumsi dengan hasil penelitian yang menunjukkan pengetahuan responden yang tergolong kategori berpengetahuan kurang hal ini menunjukkan kurangnya suatu pembelajaran, pengalaman atau pengetahuan sebelumnya mempunyai pengaruh terhadap tingkat pengetahuan keluarga yang memiliki anak PAUD yang belum pernah menerima informasi tentang penanganan ADHD sebelumnya.

\section{Gambaran tingkat pengetahuan keluarga tentang Attention Deficit Hyperactivity Disorder (ADHD)}

Berdasarkan hasil penelitian tingkat pengetahuan yang dimiliki responden tentang Attention Deficit Hiperactivity Disorder (ADHD) sebanyak 55 orang $(19,6 \%)$ memiliki pengetahuan dengan kategori baik, sebanyak 107 orang $(38,2 \%)$ memiliki pengetahuan dengan kategori cukup, sebanyak 128 orang $(42,2 \%)$ memiliki pengetahuan dengan kategori kurang. Hasil penelitian ini sejalan dengan penelitian sebelumnya yang dilakukan oleh Ardiyanti (2014) tentang pelatihan pemahaman ADHD bagi orangtua dan guru untuk meningkatkan kemampuan deteksi dini, hasil penelitiannya didapatkan 8 dari 10 wali murid yang diwawancarai oleh peneliti menyatakan tidak mengetahui tentang ADHD. Menurut teori Hinshaw \& Scheffler (2014) akan muncul stigma negatif yang tidak terkontrol apabila orang tua yang memiliki intensitas komunikasi lebih tinggi dengan anak tidak mampu mengidentifikasi atau mendeteksi dini kondisi yang dialami anak oleh sebab itu kemampuan orangtua dalam mendeteksi dan penanganan dini secara tepat terhadap anak dengan gejala ADHD menjadi penting.

Menurut Notoadmodjo (2012) pengetahuan merupakan hasil dari tahu dan ini terjadi setelah seseorang melakukan penginderaan terhadap suatu objek tertentu. Penginderaan terjadi melalui panca indera manusia yang terdiri dari indera penglihatan, pendengaran, penciuman, rasa dan raba. Sebagian besar pengetahuan manusia diperoleh melalui mata dan telinga. Responden yang berpengetahuan baik sesuai dengan metode nonilmiah dalam memperoleh pengetahuan yaitu berdasarkan pengalaman pribadi seseorang dapat memperoleh pengetahuan melalui cara mengulang kembali pengalaman yang 
diperoleh dalam memecahkan permasalahan yang dihadapi pada masa lalu. Tingkat pengetahuan ini termasuk tingkat "memahami" dimana seseorang mengingat kembali materi secara spesifik dari seluruh bahan yang dipelajari sehingga seseorang mampu untuk menjelaskan, memberikan contoh dan menyimpulkan objek yang dipelajari. Responden yang berpengetahuan cukup sesuai dengan metode nonilmiah dalam memperoleh pengetahaun yaitu trial dan error. Berdasarkan beberapa kemungkinan seseorang terus mencoba kemungkinan itu untuk memecahkan masalahnya dan memperoleh pengetahuan dari hasil percobaan. Responden berpengetahuan kurang sesuai dengan metode nonilmiah dalam memperoleh pengetahuan yaitu secara kebetulan. Kemungkinan penemuan pemecahan suatu materi terjadi karena suatu kebetulan atau tidak disengaja (Notoadmodjo, 2010).

Hasil penelitian ini berbanding terbalik dengan hasil penelitian yang dilakukan oleh Elizawarda (2015) tentang gambaran tingkat pengetahuan ibu tentang gangguan pemusatan perhatian hiperaktif (GPPH) di TK Bidayatul Hidayah Medan. Tujuan dari penelitian ini adalah untuk mengetahui tingkat pengetahuan ibu yang mempunyai anak hiperaktif. Rancangan metode dalam penelitian ini menggunakan metode deskriptif. Hasil penelitian ditemukan bahwa dari 30 responden yang memiliki pengetahuan baik sebesar 10 responden (34\%), yang memiliki pengetahuan cukup sebanyak 12 responden (40\%) dan yang memiliki pengetahuan kurang sebanyak 8 responden (26\%).

Peneliti berpendapat bahwa responden dengan pendidikan perguruan tinggi menunjukkan tingkat pengetahuan kurang dikarenakan responden hanya paham pada konsep dasar ADHD saja dan mayoritas responden yang memiliki pengetahuan kurang karena minimnya paparan informasi tentang deteksi dini serta penanganan ADHD sehingga informasi tersebut tidak mampu diuraikan dan dijelaskan. Hasil penelitian ini sejalan dengan teori Hinshaw \& Scheffler (2014) yang mengatakan bahwa informasi mengenai ADHD pun sangat minim tersosialisasikan kepada orangtua hal ini membuat mereka kesulitan mendeteksi dini ADHD karena ketidakmampuan dalam mengidentifikasi mereka cenderung memberikan label negatif terhadap anak-anak dengan ADHD. Keluarga adalah kunci utama dan terpenting dalam mendeteksi, manangani, merawat dan mendidik anak agar kelak dampak negative dari perilaku ADHD dimasa depan dapat dikontrol.

\section{SIMPULAN}

\section{SIMPULAN DAN SARAN}

Kesimpulan hasil penelitian ini adalah dari 23 PAUD di Kecamatan Denpasar Utara didapatkan 280 responden yang kooperatif dalam mengumpulkan data kuesioner.

Hasil penelitian didapatkan tingkat pengetahuan responden tentang konsep dasar ADHD menunjukkan 131 orang (46,5\%) memiliki tingkat pengetahuan baik, tingkat pengetahuan responden tentang deteksi dini ADHD menunjukkan 116 orang $(41,1 \%)$ memiliki tingkat pengetahuan kurang, tingkat pengetahuan responden tentang penanganan ADHD menunjukkan 114 orang (40,7\%) memiliki tingkat pengetahuan kurang dan tingkat pengetahuan responden tentang ADHD di PAUD Kecamatan Denpasar Utara menunjukkan 128 orang $(42,2 \%)$ memiliki tingkat pengetahuan kurang. 


\section{SARAN}

Berdasarkan kesimpulan hasil penelitian di atas, maka saran yang dapat disampaikan adalah sebagai berikut : Kepada perawat anak diharapkan dijadikan pedoman dan mampu memberikan pengetahuan kepada perawat anak sebagai educator dan konselor dalam memberikan edukasi mengenai cara mendeteksi secara dini dan penanganan anak dengan ADHD, sehingga dampak negative dari perilaku ADHD dapat diatasi lebih dini. Kepada kepala puskesmas diharapkan penelitian dapat digunakan sebagai masukan bagi bidang kesehatan seperti puskesmas dalam rangka meningkatkan upaya-upaya berupa panduan seperti leaflet yang disediakan disarana kesehatan tentang cara mendeteksi dini dan penanganan anak ADHD sehingga keluarga yang memiliki anak usia dini lebih terpapar informasi tentang ADHD. Kepada kepala keluarga diharapkan dapat memberikan masukan kepada seluruh masyarakat berupa health education bagi keluarga khususnya orang tua yang memiliki anak usia dini dan bagi orang tua dengan anak berkebutuhan khusus salah satunya ADHD mengenai konsep dasar, deteksi dini dan penanganan yang tepat sehingga diharapkan dampak negative dari perilaku ADHD dapat dideteksi dan ditangani lebih dini. Kepada pengelola media internet hasil penelitian ini menunjukkan bahwa selain mayoritas responden yang menjawab tidak pernah mendapatkan informasi, mayoritas responden juga menjawab mendapatkan sumber informasi dari internet. Diharapkan skripsi ini nantinya dapat dipublikasikan di internet sehingga semakin banyak responden yang dapat menggali informasi tentang ADHD karena internet sangat potensial sebagai sumber informasi di era modern ini. Kepada peneliti selanjutnya hasil penelitian ini diharapkan dapat menambah pengetahuan sebagai data dasar untuk melaksanakan penelitian lebih lanjut yang berkaitan dengan ADHD. Peneliti selanjutnya diharapkan dapat melakukan teknik pengumpulan data yang lebih mendalam dengan cara melakukan observasi atau wawancara untuk mendapatkan data yang lebih lengkap serta perlu dilakukan penelitian yang lebih luas tidak hanya dilakukan di PAUD Kecamatan Denpasar Utara saja tapi di kecamatan lainnya di Kota Denpasar sehingga dapat menggeneralisasi pengetahuan keluarga tentang ADHD di Kota Denpasar.

\section{DAFTAR PUSTAKA}

Adiputra, I.M.S., Sutarga, I.M. \& Pinatih, G.N.I., 2015. Faktor Risiko Attention Deficit Hyperactivity Disorder ( ADHD ) pada Anak di Denpasar., 3, pp.43-48.

Arningsih, A.A.D.R., 2016. Hubungan Gangguan Pemusatan Perhatian Dan Hiperaktivitas Pada Anak Terhadap Kejadian Depresi Ibu Di Sekolah Swasta Denpasar.

Apriliya. 2017. Gambaran Angka Kejadian ADHD Di Sekolah Inklusi Denpasar. Aherson, P. 2012. Under diagnosis of adult ADHD : cultural in fluences and societal burden. J Atten Disord: 20S-38S.

Ardiyanti. 2014. Pelatihan Pemahaman ADHD Bagi Orangtua dan Guru Untuk Meningkatkan Kemampuan Deteksi Dini.

Asmira, V. 2015. Anak Hiperaktif. Yogyakarta : Andi Offset. 
Baihaqi, M. \& Sugiarmin, M. 2010. Memahami dan Membantu Anak ADHD. Bandung : Refika Aditama.

Chrisna, F. 2014. Terapi Dan Bimbingan Menulis Untuk Anak ADHD. Yogyakarta : Redaksi Maxima.

Delphie, B. 2009. Layanan Perilaku Anak Hiperaktif. Jogjakarta : PT Intan Sejati Klaten.

Effendy. 2007. Ilmu Komunikasi, Teori Dan Praktek. Bandung : Remaja Rosdakarya.

Elizawarda. 2015. Gambaran Pengetahuan Ibu tentang Gangguan Pemusatan Perhatian Hiperaktif (GPPH) di TK Bidatul Hidayah Medan.

El-nemr, F.M., Badr, H.S. \& Salem, M.S. 2015. Prevalence of Attention Deficit Hyperactivity Disorder in Children., 3(2), pp.274-280.

Friedman, M. 2010. Buku Ajar Keperawatan Keluarga: Riset Teori Dan Praktek. Edisi Ke-5. Jakarta : EGC.

Frisch. 2010. Psychiatric Mental Health Nursing. (3Rd edition). Canada : Thomsom Dlmar Learning.

Hidayat, A.A.A. 2009. Metode Penelitian Keperawatan dan Teknik Analisa Data. Jakarta : Salemba Medika.

Hinshaw, S. P., \& Scheffler, R. M. 2014. The ADHD Explosion Myths Medication, Money, And Today's Push Performance. New York : Oxford University Press.

Umar, H. 2014. Metode Penelitian Keperawatan untuk Skripsi dan Tesis Bisnis, Edisi-2 Cetakan ke-13. Jakarta : Rajawali Pers.

Galih. 2011. Hubungan GPPH (Gangguan Pemusatan Perhatian Hiperaktifitas) Dengan Prestasi Belajar Siswa Di SDN Perumnas Bumi Kelapa Dua Tanggerang.

Notoadmojo, S. 2010. Ilmu Perilaku Kesehatan. Jakarta : PT Rineka Cipta.

Notoatmodjo, S. 2011. Kesehatan Masyarakat. Jakarta : PT Rineka Cipta.

Notoatmodjo, S. 2012. Metodologi Penelitian Kesehatan. Jakarta : PT Rineka Cipta.

Nugroho. 2014. Efek Brain Gym Dalam Meningkatkan Perhatian Anak ADHD.

Nursalam. 2013. Konsep dan Penerapan Metodologi Penelitian Ilmu Keperawatan. Jakarta : Salemba Medika.

Nursalam. 2016. Konsep dan Penerapan Metodologi Penelitian Ilmu Keperawatan. Jakarta : Salemba Medika.

Meliono dan Irmayanti. 2013. MPKT Modul 1. Jakarta : Lembaga Penerbitan FEUI. hal. 1

Paternotte, A.J. \& Buitelaar. 2010. Attention Deficit Hyperactivity Disored (ADHD). Jakarta : Prenada.

Putra, Y.A. 2014. Pengaruh Program Back In Control Terhadap Tingkat Kedisiplinan Anak ADHD Usia Sekolah Di Kabupaten Badung. STIKES Wira Medika PPNI Bali.

Putri, A. 2014. Pelatihan Pemahaman ADHD Bagi Orangtua Dan Guru Untuk Meningkatkan Kemampuan Deteksi Dini Sekar Putri Ardiyati. Pp.2-18.

Hidayati, R. 2014. Peran Konselor Sekolah Dalam Meningkatkan Konsentrasi Pada Siswa Hiperaktif (ADHD).

Riwidikdo. 2009. Statistik Penelitian Kesehatan. Yogyakarta : Pustaka Rihama.

Sadock \& Kaplan. 2015. Synopsis Of Psychiatry: Behavioral Scienes/Clinical/Psychiatri-Elevent Edition. 
SAK Indriyani, Soetjiningsih, IGA Endah Ardjana, I.T.W. 2008. Prevalensi dan Faktor-Faktor Risiko Gangguan Pemusatan Perhatian Anak dan Hiperaktivitas di Klinik Tumbuh Kembang RSUP Sanglah Denpasar. 9(5), pp.335-341.

Saputro, D. 2009. ADHD (Attention Deficit / Hyperactivity Disorder). Jakarta : Sagung Seto.

Setiadi. 2013. Konsep Dan Praktek Penulisan Riset Keperawatan, Edisi 2. Yogyakarta : Graha Ilmu.

Soekanto. 2013. Sosiologi Suatu Pengantar. Jakarta : Rajawali Pers.

Sugiyono. 2016. Statistik Untuk Penelitian. Bandung : Alvabeta.

Sukawana. 2009. Pengantar Statistik Untuk Perawat. Denpasar : Poltekes Jurusan Keperawatan Denpasar.

Widayatun. 2009. Ilmu Perilaku. Jakarta : Info Medika.

Windasari, K.A. 2013. Pengaruh Bercerita Dengan Alat Peraga Papan Flannel Terhadap Perkembangan Menyimak Pada Anak Dengan ADHD. STIKES Wira Medika PPNI Bali.

Wiyani, 2014. Buku Ajar Penanganan Anak Usia Dini Berkebutuhan Khusus. Yogyakarta : Ar-Ruzz Media.

Wiyani, N.A. 2014. Buku Ajar Penanganan Anak Usia Dini Berkebutuhan Khusus. Yogyakarta : Ar-Ruzz Media. 